\title{
O terceiro texto: etnia e ficção em Adonias Filho
}

\section{Vera Lúcia Romariz Correia de Araújo}

O diálogo de culturas que constituiu a formaçào do povo brasileiro compôs a forma étnica sobre que Adonias Filho construiu sua ficção. A tradiçào oral que nos veio da herança grega e que também subsidiou as culturas africana e indígena, ao lado de um sagrado judaico-cristào e das culturas orais citadas, compuseram essa extensa rede cultural que o escritor representou.

A relaçào entre a forma étnica e a romanesca, no entanto, nào é linear; Adonias Filho rompe, conscientemente, com a assimetria de nosso processo colonizador, pondo todos os grupos culturais em situaçào nào hegemônica. Evita a supervalorizaçào da cultura branca européia e o caminho oposto: a idealizaçào compensatória dos grupos indígena e africano. A todos atribui voz narrativa e condiçào de heróis, mesclando no mundo reapresentado fragmentos de heranças culturais variadas, como quando reedita, em Léguas da Promissão, o episódio bíblico da fuga de Moisés com o povo judeu, substituindo o líder hebreu pela negra Simoa - misto de líder histórica e Iemanjá. A referência ao Êxodo é clara, o que se observa na saída pelas águas e na magia de abrir o caminho para fugir com o seu povo.

Um segundo que foi tempo muito para sua viagem. Rodou, nesse segundo, os mares de Ilhéus sem ihamar Olokeum. Viu sua força nas marés, na agitação das ondas, zangada estava. [...] Recuaram, todos, permitindo que ela fizesse a estrada. E debaixo dos seus pés, onde pisava, a água nascia, água doce, como se viesse de Oxum. [...] Continuou andando, Naro a seu lado, atrás os negros. Viram, todos viram quando sumiram no fundo da. fronteira, em caminho do mar: (L.P.: 147)

Adonias atua como um "transculturador narrativo" (Cf. Rama, 1975, p. 74) da literatura latino-americana, mediando o diálogo da cultura brasileira com os seus sub-grupos internos e com outras culturas. Seu projeto de autoria é o de um sujeito étnico (Cf. Leroy-Gourhan. op. cit.), que se desobriga de representar grandes dramas pessoais para fazer-se um cantor de histórias coletivas. A escrita adoniana é, pois, adensada por essa intençào de um projeto literário partilhado com a história cultural: é um terceiro texto, como nomeou Anatol Rosenfeld (op. vit.: 109) a escrita de Mário de Andrade, situado entre a etnografia e a literatura. Quando Adonias Fillho realiza, 
no nivel da composiçào romanesca, o que denominamos de "terceiro texto", ele supera o nível temático e avança consideravelmente no domínio da representaçào da cultura brasileira e ocidental. Filiado a uma tradiçào de que fizeram parte românticos como Gonçalves Dias e José de Alencar, além de realistas como Franklin Távora (1997), Adonias avança nesse processo construindo categorias que dialogam com os mais avançados escritores latino-americanos no domínio da escrita literária; nesse rol do que chamariamos transculturadores da literatura do continente, sobressaem os brasileiros Mário de Andrade, Guimaràes Rosa e, evidentemente, o escritor baiano.

A forma literária adoniana, no esforço que empreende para representar a forma étnica, apresenta procedimentos comuns a toda sua obra e procedimentos relativos a cada tradiçào incorporada, como a composição de personagens em queda, influenciadas pela noçào judaico-cristà do pecado. Sào recorrentes na sua ficçào a descontinuidade espaço-temporal, o narrador móvel, os prefácios poéticos e uma permanente (mas nào reverente) atualizạico das tradiçoes representadas, de que trataremos a seguir.

\section{1-A descontinuidade espaço-temporal}

A descontinuidade de espaços e tempos culturais, já apontada como própria da literatura latino-americana por Ana Pizarro (1993), integra sobretudo a composiçào do romance Luanda Beira Babia, de 1972. Na abertura, o narrador avisa que, de tào antigo, esse tempo narrativo tem "uma idade impossivel de saber-se" (L. B. B.: 3); logo em seguida a essa referência mítico-temporal, lança duas temporalidades. Uma é a do Gênesis, que influencia o início do enunciado; outra é a referência ao tempo da descoberta do Brasil, que o Autor chama de "tempo das caravelas".

Teria visto a praia ainda selvagem, o Pontal com três choupanas e Ilhéus sem o porto. Canoas, remos nas mãos de escravos e indios, o mar com a serenidade de um lago. (ibidem)

Nessa obra, viajamos com o enunciado por épocas e continentes distintos, reeditando, na forma literária, o percurso étnico de nosso processo colonizador e o diálogo de culturas que o subsidiou. Com o barco do menino Caúla - filho de europeu e màe cabocla - viajamos por Luanda, na África, por Beira, em Portugal e por Ilhéus, na Bahia. () que se poderia configurar como uma busca individual do pai europeu-vagabundo errante, se adensa na noçào de que esse trajeto é, igualmente, 
uma busca do entendimento das vozes que nos formaram. A própria história da origem do menino Caúla confunde-se, simultaneamente, com um diálogo de culturas e com nosso processo híbrido de formaçào histórica.

O pai de Caúla que, na narrativa, tem três nomes, conforme o lugar onde finca provisórias raizes, chama-se Sardento e Joào Joanes no Brasil e Vicar na África. Uma identidade móvel como seu processo de viajante.

Disseram que ele, o Sardento, tinha o doido sangue dos marinheiros herdados do pai, avô e bisavô. Cabocla de Olivençal era, filha daqueles indios, gostando de paisagem de mato. (ibidem: 10)

A mobilidade de espaços conduz, na narrativa de Luanda, a uma permanente transposiçào de fronteiras, o que se pode verificar nas reiteradas alusòes a seres e lugares estrangeiros a partir de uma ótica do autóctone. Com o deslizar entre uma perspectiva do próprio e do estranho, a autoria adoniana introduz, no cerne da enunciaçào, o diálogo de culturas. Para Ana Pizarro (1993), essa descontinuidade espaço-temporal é intensa na literatura da América Latina porque nossa formaçào étnica teve tempos culturais diversos e às vezes antagônicos, dai resultando, na ficçào, um discurso recortado por uma simultaneidade de enredos em tempos e espaços diversos. É o caso dos romances Luanda Beira Bahia e As Velhas, mais especificadamente,

Outras narrativas do Autor também nos possibilitam essa viagem por tempos e espaços diversos. Cajango, em Corpo I ivivo, fugindo dos assassinos de sua família, atravessa espaços urbanos e rurais, optando por estes últimos, na simbólica busca do ninho perdido.

I 'ajamos assim duas semanas, ou mais, e em nossas costas foram ficando os arruados e as fa quendas. As estradas foram se afastando, tornandose veredas [...] O mundo, vocês sabem, é uma rede [...] Era esperar que impossível serva encontra-lo na sella que vinba do principio do mundo. (C.V.:18)

Mesmo quando se refere a um espaço geograficamente localizado como Camacà $^{2}$, o narrador joga com outro espaço e tempo: o mítico, da cosmogonia,

'Olivença é uma praia de Ilhéus, na Bahia.

2O termo indigena indica tanto uma tribo quanto uma atual cidade do sul da Bahia, próxima a I tajuipe, onde o escritor nasceu. 
que relaciona esse espaço rural ao do princípio do mundo. Tanto os mitos gregos, mais antigos, quando os indígenas e africanos, fazem referência a esse tempo primordial, do início da vida: em todos eles, o espaço natural é o cenário escolhido como locus privilegiado de surgimento de seres e coisas, como ocorre, inclusive, no éden judaico.

No romance As Velhas, a índia Tari Januária pede ao filho que parta em busca dos ossos do pai; e todo o livro, então, converte-se em mais uma viagem adoniana, com o herói Tonho Beré buscando entender a si mesmo e aos longos relatos orais das índias velhas - guardiàs dos segredos de seu povo. Cada fala dessas mulheres é pronunciada em espaços diferentes, em conformidade com a cultura cuja memória expressam.

Em Léguas da Promissão - livro constituído por seis novelas -, "Simoa" representa um exodo do povo negro, enquanto que "Imboti" constitui uma longa viagem ao passado para entender o trágico assassinato da jovem índia Imboti por um homem albino. A tragédia dessa bela índia camacà poderia reduzir-se a um drama individual, mas o narrador, apresentando o algoz como um branco degradado (albino), reitera uma percepçào de encontro de culturas a que Octavio Paz faz referência: o complexo da Malinche, que mostra, na concepção indígena, o branco colonizador como um ser que estupra e macula a identidade indígena.

A descontinuidade espaço-temporal, no mundo representado, constitui uma reduçào estrutural e estilística do diálogo de culturas que nos constituiu enquanto povo híbrido. Aquilo que no universo referencial ocorreu em tempos e espaços muito heterogêneos se atualiza no tecido romanesco na construçào de uma temporalidade e espacialidade múltipla, descontínua, como ocorre nos romances adonianos, sobretudo em Luanda Beira Bahia. Nesta obra, no curto espaço de tempo da vida do brasileiro Caúla, ele vive experiências no solo brasileiro de Ilhéus, em Moçambique e em Luanda, como se o seu percurso ficcional correspondesse ao percurso do próprio país em sua formaçào cultural híbrida, com a assimilaçào de vários aportes étnicos.

Além de Luanda Beira Bahia, o romance O Forte, publicado em 1965, é um significativo exemplo deste procedimento. Nele, no cenário urbano de Salvador, conta-se, através da voz do velho negro Olegário a história de amor de Jairo e Tibiti e a de seus pais Michel e Damiana. O forte representado no romance foi, no passado, cenário de guerras e massacres e uma prisào onde ficou o velho Olegário, ao assassinar o violento genro Michel.

Na narrativa, o forte funciona como a referência que permanece no presente, mas que, de forma reiterada, detona um entrecruzamento de tempos e ações 
descontínuas, retomadas pela voz do velho Olegário. Na verdade, a história da construçào do forte confunde-se com a da colonização baiana e das guerras da independência, onde as maiores vítimas são os escravos negros e os índios chacinados pela armada. Tudo isto é relatado quer através da voz do velho negro, que presenciou alguns dos fatos, quer através da voz do narrador, sempre em tempos e espaços diversos, com flash-backs reiterados, como se o presente narrativo fosse insuficiente para esclarecer todos os fios da densa trama.

O grande portão aberto, Jairo o transpõe, Tibiti a seu lado, e o que disse atinge o pátio antes dos próprios pés. [...] $\mathrm{O}$ corredor, nele avançam, os passos repercutem. Outros, centenas de outros, estiveram ali. Ele, o Forte, conbece os homens. Muito foi o tempo com uma bumanidade dentro. Reinou a morte com as guerras e as pestes. Noites de caridade, dias de violencia, todas as vozes ainda no ar. Espécie de gás, entre as paredes, o Forte fechado. (Ft.: 1, grifos nossos)

A imagem - extremamente significativa - de que as experiências dolorosas do passado se instalam como um gás no tempo e espaço presentes, ressalta a descontinuidade temporal que é recorrente em todo o romance.

Do ponto de vista da descontinuidade espacial, o narrador dessa obra, referindose ao espaço de Salvador, mais urbanizado, lembra que o espaço antigo invade a nova paisagem. A superposiçào dos planos espaciais como que adensa o cenário contemporâneo, com o forte simbolizando os espaços e tempos antigos, mas nào mortos.

Novamente andam [...] sobra o tempo. A rua do comércio, passeios, largos, iluminadas as vitrinas. Não importam as horas, o céu mostrando as estrelas, os automóveis que passam. [...] Os manequins, os anúncios luminosos, as esquinas. Dir-se-ia que sobre ele e a Bahia paira a sombra do Forte. (Ft.: 124, grifos nossos)

\section{2-Narrador móvel}

A essa descontinuidade ${ }^{3}$ espaço-temporal, junta-se a categoria de um

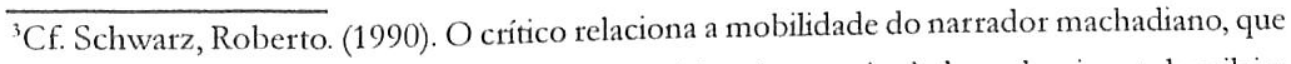
denomina de volubilidade, a um movimento histórico circunscrito à classe dominante brasileira e à teia de relações que estabelece com outras classes, de onde avulta a ausência de estabilidade social, muito bem captada por Machado de Assis. 
narrador móvel, cúmplice narrativo do movimento étnico. Mobilizando-se em conformidade com os tempos e espaços culturais diversos, o narrador impregnase dos valores, ritmo e retórica dos grupos envolvidos; desse jogo, resulta uma funçào importante do narrador adoniano, que tem traços sofisticados do enunciador moderno e marcas indubitáveis do antigo contador de estórias orais. Uma mobilidade que faz interagirem a tradiçào e o tempo presente.

Com a exaustiva recuperaçào das tradiçòes orais a que se propòe, o projeto de autoria de Adonias Filho tenta resgatar a perda do contador de estórias e seu intercâmbio de experiências que Walter Benjamin (1994a) assinalou na narrativa contemporânea. Adonias tenta fugir à noçào isolacionista do narrador moderno instalando, no cerne da enunciaçào e do enunciado, como retórica e personagem, a figura do contador de estórias que relata experiências comuns aos ouvintes e à memória das culturas envolvidas. O narrador móvel, na ficçào adoniana, é também o correlato do mundo cultural; como este é complexo, constituído de movimentos de tensào externa e interna, o ritmo enunciativo se modifica em conformidade com os fatos culturais que representa.

O melhor exemplo dessa categoria, a nosso ver, é o da perspectiva com que a África é mostrada no romance Luanda Beira Babia. No início, a voz de Corina Mulele, màe negra da mestiça Iuta, está impregnada pelo olhar eurocêntrico sobre a paisagem africana, mostrando os autóctones como inferiores e o colonizador como um ser poderoso e fascinante. Corina Mulele precisa sair da aldeia para descobrir a beleza e força das próprias raízes e esse aprendizado da África vem aos poucos; a imagem que faz da própria màe é negativa inicialmente, opondo-se ao fascínio que o pai ausente exerce.

a mãe sentada no almofadão, tão gorda e enorme que era quase um bipopótamo. [...] Filho de Portugal, forte e valente, não entendia o que ele, o pai, encontrara em sua mãe. Não, não entendia! (L.B.B.: 44)

Quando Corina Mulele resolve deixar a aldeia e o núcleo familiar, indo morar em Luanda, o narrador avisa que o sangue do pai a chamava para o mar; mas ć a partir dessa viagem que o narrador se mobiliza e enuncia um novo olhar sobre a paisagem africana, despindo-se da perspectiva eurocêntrica. Como se Corina Mulele se dirigisse à filha, a enunciaçào prossegue em um ritmo impregnado pela alegria da descoberta; exclamaçòes em dialeto africano se repetem.

Euê, Iula, foi assim! (... I'iagem comprida, as estradinhas onde mal cabiam as pés. [...] Tudo ele mostrava, Capulo, alegre e animado, 
conhecedor dos caminhos: Bom como um santo, muito feliz por descobrir para mim os caminhos de . Angola, preso à selva como as mulembas. [...] nós que vinhamos do Mussende, Quibala e Gabela e iamos para Luanda. [...] Tínhamos vontade no coração, fé em Luanda, acreditávamos na vida. (ibidem: 48)

A aprendizagem da África é um processo gradativo cujas nuances se podem entrever na voz do narrador; para o brasileiro Caúla, ela também vem aos poucos, na voz da professora negra Maria da Hora, quando esta lhe ensina a localizaçào da África no mapa. A câmera móvel do narrador, entào, antes tingida de eurocentrismo, é inundada pela paisagem e valores africanos.

Mas quando o livro Luanda Beira Babia se inicia, o narrador está impregnado de uma visào eurocêntrica e patriarcal; o europeu que chega se sente e é sentido como o dono de um espaço onde existem "apenas" índios nômades. Percebe-se que o narrador, nesse momento, autoriza a superioridade do europeu sobre os nativos como se, entranhados em sua voz, se instalassem os valores da cultura branca, européia e hegemônica.

Mas, embaixo, o que pudesse sentir como um vizinho - a não ser um outro grupo de indios que raramente acampava -, nada, nada mesmo. Isso até uma manhã quando o homem andou no chão, indo e voltando, como o dono. (ibidem: 4 , grifos nossos)

Essa noçào de superioridade da cultura branca européia de que o narrador se impregna é partilhada com Morena, cabocla filha de índios e màe de Caúla. O narrador refere-se aos descendentes de índios pejorativamente e - ancorado em sua perspectiva - torna-se cúmplice do fascínio da índia diante do branco que chega.

Ali no baile, no meio da caboclada de cabelos pretos e lisos, ele tinha que chamar a atencião. A cara sardenta e vermetha de galo de brigu, a cabeçala alourada, azulão nos olhos. [...] Foi aquele bonito azulão dos olhos que a prendeu [...] Não teve dívidas, pois, de que o homem chegara, o pai de seus filhos, o dono. (ibidem: 10, grifos nossos)

A movimentaçào do narrador dá-se em vários planos, coadunando-se com o ritmo da diversidade cultural. Claude Lévi-Strauss lembra que a diversidade cultural ocorre com culturas em relaçào e no interior de cada cultura, com a diversificaçào e estratificaçào de cada subgrupo cultural. 
Em Adonias Filho, percebemos que a mobilidade do narrador acompanha ora momentos de culturas em relaçào, como nos exemplos citados, ora a diversidade social que se instala no interior das culturas, como no caso da cultura popular. No livro O Largo da Palma (1981), que reúne seis novelas ambientadas no cenário urbano de Salvador, tipos populares sào apresentados pelo narrador, que se impregna de seus valores e retórica.

Negra como ele, mais velha que ele doze anos, de tantas coisas entendia que era a sabedoria em pessoa. Sanfoneira, jogadora de baralho e dados, cantora nas ruas do cais, puta aos sábados, cartomante e rezadeira, mulher sem pouso certo que apenas tinha de seu o maior coração da Babia. (L.Pa.: 49, grifos nossos)

- Eu gosto é da gandaia! - exclamava, os olhos acesos, os lábios carnudos: (ibidem: 50)

A personagem Aparecida, velho amor do negro Loio, constitui uma espécie de síntese de elementos muito caros à ficçào de Adonias, como o saber que nào se encontra nos livros e que é patrimônio da oralidade, dos cantores e "sacerdotes" do povo, que apreendem "com o coração" as verdades pouco acessiveis ao saber letrado. O narrador adoniano, deslocando-se dos momentos de culturas em relaçào, chega ao porto popular e a ele, enfaticamente, atribui legitimidade. Para Alfredo Bosi (1992a) a cultura criadora dos artistas e a cultura popular têm ponto importante de convergência: elas se afastam do olhar normatizador das instituiçòes. Um bom exemplo disso é a encantadora Aparecida, amor jamais esquecido pelo velho negro Loio, que é prostituta, cantora e rezadeira; na tríplice atividade, a tríplice transgressào aos saberes instituídos.

\section{3-Atualização das tradições representadas}

A relaçào que Adonias Fillho estabelece com as tradiçòes culturais do Ocidente nào está isenta de atualizaçòes. Podemos dizer que - mesmo no caso dos mitos ele interfere a partir de uma perspectiva de degradaçào ou de transformaçào; o que caracteriza, no entanto, esse atualizar adoniano é um foco sob o qual filtra seus enunciados. Este é o do presente histórico, expresso em elementos que situam seu enunciado na atualidade da região do sul da Bahia, imersa em conflitos de terra que o narrador, a cada passo, representa, o grande móvel que impulsiona a voz do 
presente histórico na narrativa é a luta pelo território. Em Corpo Vivo, o velho Alonso, amigo dos pais de Cajango antes de estes serem assassinados, prevê a tragédia e seus motivos, de base econômica.

"O mundo é muito grande - Alonso disse - mas querem as terras de Januário." [...]. Alonso respondeu a todas [perguntas] esclarecendo que o. Bilá, após certas brigas com Januário, tinham jurado lhe tomar as terras. $O$ cacau novo de Januário comecava a dar frutos. Aquelas terras valiam ouro e os Bila tinham um exército no rifle. (C.V.: 5)

A cultura do cacau - relativamente recente no sul da Bahia - nào se fez placidamente; Jorge Amado, no livro Tocaia Grande (1987) representa essa tensão social extremamente violenta que adveio da modificaçào das antigas matas para a chegada de uma nova cultura. Com o cacau, vieram os conflitos com índios da regiào, antigos ocupantes, mostrando que as tensòes invadem o campo e seus espaços mais recônditos; por esta razào, o ambiente rural que surge em quase todos os romances de Adonias nào é um locus amoenus, mas um espaço de lutas e sofrimentos. Pode-se dizer que, ao evitar a representação do rural como um espaço idílico, Adonias atualiza sua narrativa a partir de uma impregnaçào do presente histórico, como no caso de "Simoa".

Em todo o território a terra com os donos. Os caçadores em guerra, matando e morrendo, por um pedaço de selva. Um palmo de chão livre já não havia, os rifles atrás do arame farpado, a terra dividida e ocupada. (C.V.: 129, grifos nossos)

Ao evitar, conscientemente, utilizar o bucolismo literário com a conotaçào positiva e harmônica, mas estritamente convencional que o neoclassicismo utilizou, Adonias Filho mostra-nos que o ambiente rural é seu espaço de eleição, mas nào tem com ele intençòes nostálgicas. Para Raymond Williams (1990), que estudou o bucolismo na história e na literatura, essa tradiçào é muito antiga e remonta a Hesíodo, no século IX A.C., o que o crítico ressalta é que, muitas vezes, essa convençào se desprega demais das realidades históricas que a circundam. Citando Virgílio como exemplo de alguém que atualizou essa tradiçào ao introduzir "perturbaçòes ocorridas na vida rural de sua Itália" (Williams, 1990), Williams faz-nos ver que alguns autores - como Adonias Filho - interferem na tradiçào, atualizando-a e renovando-a.

A análise da representaçào do espaço no Autor mostra-nos que ele se afasta dos procedimentos do regionalismo do século XIX e dos que caracterizaram o 
segundo esforço regionalista no Brasil. Em que pese a importância que Adonias atribuiu, em seus ensaios, a certo enraizamento geográfico da ficçào brasileira, sua produçào literária, de caráter transcultural e universal, transcende o específico e o local.

Um outro procedimento utilizado pelo autor para atualizar sua narrativa é o do uso de categorias negativas - infringindo, claramente, o veio eufórico do Modernismo de $22 \mathrm{~cm}$ uma de suas vertentes, capitaneada por Graça Aranha e Menotti del Picchia. ${ }^{+}$Estes autores, que elegeram o desenvolvimento tecnológico e o espaço urbano como o cenário ideal, pouco têm a ver com o ideário adoniano; para este, a cidade não é tema, nem escolha, e quando surge em seus romances apresenta uma face impregnada de ruralismo, com seus tipos populares, marginalizados e anônimos cantando um campo vivo na memória. A concepçào do campo, em Adonias, ratifica uma posiçào de Mário de Andrade que, no Ensaio sobre a música brasileira, registra a penetraçào do elemento rural em nossos núcleos urbanos, o que se evidencia em expressòes de cultura popular. Para Mário, "todas as cidades brasileiras estào em contato direto e imediato com a zona rural" (1962: 166), permanecendo em muitas delas um espírito rural.

O uso de categorias negativas, quando associado ao uso do ruralismo, impede Adonias Filho de recair no vezo de um regionalismo reducionista; mas, igualmente, o diálogo com outras culturas também o afasta da perigosa celebraçào de regiòes em que incorreram bons autores como José de Alencar e Franklin Távora (1997). O específico, em Adonias, entrecruza-se com outros diferentes a cada passo; dessa tensão produtiva, surge uma narrativa que se faz universal pelo permanente diálogo com vozes que a formaram, por que constituídas a partir de uma forma étnica múltipla que lhe serviu de instigante referência.

A atualizaçào das tradiçòes, em Adonias Fillho, configura-se como uma atitude do autor de consciência dos aspectos dinâmicos da cultura, que se mobiliza permanentemente interferindo na vida contemporânea. Tradiçào como sabedoria, como técnica que se apura no tempo, mas que também se modifica para atender às mudanças ocorridas no interior das comunidades. Mas essa atualizaçào também reflete um projeto de autoria que, sem ignorar o antigo cultural, capta os novos

'Referimo-nos, sobretudo, à conferencia proferida por Menotti em quinze de fevereiro de 1922. "E que o rufo de um automóvel, nos trilhos de dois versos, espante da poesia o último deus homérico, que ficou anacronicamente, a dormir e sonhar, na era do "jazz-band" e do cinema, com a flauta dos pastores da . trcádia e os seios divinos de Helena!" (In: Teles, Gilberto Mendonça. Vanguarda Européia e Modernismo Brasileiro, Petrópolis, Vozes, 1992). 
culturais, os nào-hegemônicos; deste modo é um instrumento de relativismo e de anti-etnocentrismo pois reconhece e expressa a dialética do processo de encontro de culturas.

Quando representa, o complexo cultural brasileiro, o Autor ratifica esse procedimento atualizador do antigo, sobretudo em relaçào aos elementos populares que representa.

É na década de 60 que Adonias Filho escreve três obras em que a cultura popular brasileira é representada, ainda que de forma não linear, em alusòes que o narrador utiliza para referir-se aos cantadores. Trata-se dos romances Corpo Vivo, de 1962, O Forte, de 1965 e do conjunto de novelas Léguas da Promissão, de 1968. Na década de 80, com $O$ Largo da Palma, o autor amadurecerá essa utilizaçào literária integrando as figuras populares à tessitura interna do texto. Em Corpo V'ivo, a imagem, com evocaçòes e alusòes, refere-se ainda a algo meio distante.

Nas tardes, porvęes, alguém cantava como a lembrarque o mundo existia fora com arrwados e mulberes, céu aberto e sol quente. (C.V.: 72)

Nos arruados, ele sabe, falarão de Cajango e cegos não faltarão para cantar swa guerra e sen amor. (ibidem: 89)

Entre o procedimento alusivo inicial encontrado em Corpo V'ivo, de 1962, e o de Léguas da Promissão, de 1968, quando as referências aos cantadores se tornam mais intensas mas ainda nào integram o corpo da personagem - o que só ocorrerá em 1981, com o Largo da Palma -, surge a obra O Forte, publicada em 1965. A figura dos cantadores, neste romance, entra no cenário urbano, se bem que sua funçào no enredo seja meio exógena, deslocada do corpo das açòes centrais: cabelhes, no contexto, evocarem o passado glorioso da Bahia e entreterem as personagens. O narrador afirma que cles nào conhecem o forte - palco nodular das açòes passadas e presentes -, mas já aparecem concreta e sensorialmente, com "palavras" e "dedos" visíveis, voz e violào.

As vozes dos cantadores com a musicia dos violōes. Evocavam os heróis da Bahia e, em torno, a multidão quieta e silenciosa. [...] Ouvir os cantadores, escutá-los perdido na multidão. [...] Guardava as palavras, via os dedos nos violóes [...] (Ft.: 13, grifos nossos)

Eu estou direndo. Os cantadores, ali no Terreiro de Jesus, não conhecem o Forte. I ou escutá-los porgue a Babia é grande, tem 
suas aventuras, e os violôes me acalmam os nervos. (ibidem: 18, grifos nossos)

Outra imagem sutil, mas significativa, da representação da cultura popular em Adonias é a presença de bonecos de cerâmica que adquirem vida no momento do encontro amoroso de Jairo e Tibiti em O Forte, como se legitimassem a relaçào, que é extra-conjugal. A animizaçào dos bonecos, de fundo mágico, já captada na literatura popular ${ }^{5}$, funciona como uma solidariedade dos subalternos.

Têm os olhos fechados, mas não repousam. Os bonecos de cerâmica se movem, saltam do nicho, correm na sala, vêm para vê-los, o homem e a mulher que respiram. [...] Poderão subir e pisar os corpos, os bonecos de cerâmica. [...] Jairo, apenas ele a satisfa igucis: Os bonecos de cerâmica retornam, voltam correndo entre os móveis, pequeninos e ligeiros, recolhem-se ao nicho. (ibidem, grifos nossos)

Em 1968, o procedimento alusivo que já evoluíra em O Forte, de 1965, avança um pouco mais no livro Léguas da Promisião. A referência aos cegos é introduzida no cerne da enunciaçào e o narrador desta obra, diferenciando-se das anteriores, afirma que os cantadores tudo sabem e que nào mentem. O autor coloca essa legitimaçào das vozes populares no lugar privilegiado de seu prefácio poético, em Léguas da Promissão, mas ainda nào as faz personagens do enredo.

Nesses três livros da década de 60 , Adonias faz que vozes subalternas se façam ouvir na narrativa; seus heróis serào louvados, mas nos arruados, ou no meio rural, espécie de locus urbano possível da cultura popular contemporânea. Pouco a pouco, essa representaçào se encaminha para a grande cidade de hoje, assim como ocorre com as migraçòes no mundo referencial; a transformaçào é sutil, mas significativa, com o autor trazendo elementos da cultura popular brasileira para a funçào de protagonistas e para o cerne do tecido enunciativo, com a voz do narrador se impregnando de clichês e de uma cumplicidade narrativa e cultural no cenário urbano.

A representaçào da cultura popular - sobretudo a do livro O Largo da Palma -, mostra que o projeto adoniano evoluiu da alusào para a formulaçào interna,

'Cf. Andersen. O escritor dinamarquês escreveu narrativas embasadas no folclore que representam esse elemento, como a do "Soldadinho de chumbo". 
sobretudo na novela "Um avô muito velho", de O Largo da Palma. Nesta narrativa, conta-se a trágica história do velho negro Loio, tocador de sanfona em Salvador, através de flash-backs de sua juventude feliz, ao lado da amante negra Aparecida e, posteriormente, sua relaçào com a neta Pintinha. Evidentemente, o autor se embasa na figura do Laio, da peça de Sófocles, marido de Jocasta. Mas ele atualiza essa universalidade trágica fazendo do Loio um artista popular, tocador das feiras, amante da vida e do corpo, que encontra a fascinante figura de Aparecida na juventude. A mobilidade adoniana tira o par amoroso grego dos salòes aristocráticos e coloca-o no Mercado Modelo - espaço dos subalternos com que o narrador se acumplicia. Faz, entào, dialogarem gregos, africanos e elementos internos, populares, da cultura brasileira.

Encontraram-se num dos portões de frente do mercado [...] a tocar sanfona, o povo em volta aplaudindo e jogando dinheiro, em notas e moedas, na toalha colorida [...] Quando ela finalmente parou de cantar; e todos se afastaram e saíram, foi o único que ali se manteve $[\cdots]$

- Os sanfoneiros! - o povo pobre, da cidade Baixa, apontava-os nas ruas. (L.Pa.: 50 e 51, grifos nossos)

A subalternidade dos artistas populares é adensada pelo autor na construçào da personagem Aparecida: "sanfoneira, jogadora de baralho e dados, cantora nas ruas do cais, puta aos sábados, cartomante e rezadeira” (ibidem: 49). Podemos dizer que a funçào de rezadeira nào a faz uma personagem ligada ao sagrado, de forma excludente, pois ela exercita esta funçào de modo pragmático, integrada às outras tantas atividades que desenvolve.

Essa subalternidade dos artistas populares adonianos, apontados na rua pelo mesmo povo pobre que encantam com seus dotes, é representada pelo autor ao lado de uma exuberancia material e sensivel e de um tom alegre e libertário que se contrapòe às formas representativas de base cristà e hegemônica, conforme registrou Mikhail Bakhtin na cultura popular medieval. Formas fartas, sensuais, coloridas, uma linguagem sem contençòes, caracterizam Aparecida - a amada prostituta dos cais baianos. A imagem dos olhos - vistos em textos antigos e românticos como a parte física que reflete o espírito - é umidificada, com o recurso sinestésico conferindo-lhe uma inequivoca marca de concretude; a caracterizaçào da voz como metálica, mas sem a valoraçào negativa que a tradiçào retórica ocidental atribuiu ao termo, adensa a materialidade sensível da configuraçào da personagem. 
- Eu gosto é da gandaia! - exclamava, os olhos acesos, os lábios carnudos. [...]

4 alegria, o riso e a coragem são partes dela quanto os seios redondos e duros. Úmida a lũ dos olhos, a voz metálica, as coxas macias. (ibidem: 46 e 51$)$

Aparecida, enquanto personagem, é um contraponto popular à representaçào de base judaico-cristà; as personagens sofridas e desencarnadas contrastam fortemente com esta bela e fascinante negra que toma, inclusive, a iniciativa de seduzir o jovem negro Loio.

E com a sanfona no ombro, a saia vermelha, o colar e as pulseiras de conchas do mar, aproximou-se para perguntar:

- Quem é este preto tão lindo? (ibidem: 50)

Uma sanfona só para o amor sem tamanho de dois coraçoes iguais. E lão imenso amor que, mesmo aos sábador, Aparecida já nào fa zúa vida de puta. Preferia abrir o baralho, sentada no chão iom seu principe negro ao lado. (ibidem: 51)

A retórica do narrador adoniano deixa-se penetrar pela retórica simples, povoada de clichês sentimentais ("tào imenso amor"), como se a fala de Aparecida encontrasse eco no cerne da própria formulaçào interna; dá-se, entào, mais que um processo atualizador, um ato de cumplicidade do autor com a subalternidade dos artistas populares, fazendo-os romanescamente atuantes. Trazendo o Laio e a Jocasta gregos para o cenário brasileiro, fazendo-os negros, teria Adonias rebaixado essa herança? Julgamos que este tratamento tem como risco intencional mostrar que as tradiçòes são móveis e se "contaminam" nos contextos sócio-culturais onde sào captadas, como lembrou Oswaldo Elias Xidieh (op. cit.).

O processo atualizador da cultura popular em Adonias poderia encerrar-se nesse tom alegre e libertário que envolve suas representaçòes populares, correndo o risco de reduzir o amplo universo referencial a uma grande ode moderna. $\mathrm{O}$ autor evita este tom encomiástico através de um simples e eficaz recurso: a história é contada pelo velho negro Loio, em significativos flash-backs, no quarto pobre dos fundos de uma casa, depois de mortas tragicamente Aparecida e sua neta. A amante assassinada e a neta estuprada contrastam, no trágico presente narrativo, com o passado feliz: dessa dialética, emerge intensa a figura de um avô que o narrador denomina, com um epíteto adequado, de "muito velho". 
O velbo, quando aquilo aconteceu, trancou-se em si mesmo. Não era bomem de conversas, sempre calado em seu canto, morando no quarto dos fundos que o pequeno quintal separava do corpo da casa. [...] . Agora, no Largo da Palma, era como se a memória estivesse no coração. Cansado ou enfraquecido, assim após setenta anos, doia o velho coração quando de Aparecida se lembrava. (L.Pa.: 45 e 50 , grifos nossos)

A cumplicidade da autoria, que parecia encantar-se com os toques de sanfona de Aparecida e do jovem Loio, volta a manifestar-se agora, na dignidade sofrida do velho Loio: como um guardiào da memória dos fatos vividos, sua voz é resgatada pelo narrador. 


\section{Referências bibliográticas}

FILHO, Adonias. (1954) Jornal de um escritor: Rio de Janeiro: MEC, (Os cadernos de cultura, 65).

(1958) Explicaçào. Anais da Biblioteca Nacional. Rio de Janeiro: 78.

(1960) Cornélio Pena. Rio de Janeiro: Agir (Nossos Clássicos, 42).

(1965a) Discurso de posse na Academia Brasileira de Letras. Rio de Janeiro: Tempo Brasileiro (Biblioteca de Estudos Literários, 2).

(1965b) Modernos ficiionistas brasileiros. Rio de Janeiro: Ediçòes Cruzeiro.

(1967) O homem de branco. Rio de Janeiro: Bertrand Brasil.

(1968a) Best Seller. Revista do Liuro. Rio de Janeiro, 11(33), p.169-170, abr-jun.

(1968b) Fogo Morto. Revista do Livro. Rio de Janeiro, 11(35), p.151, dez.

(1969) O romance brasileiro de 30. Rio de Janeiro: Bloch.

(1972a) Recepção de Otávio de Farias. Revista Brasileira de Cultura. Rio de Janeiro: MEC, 4(12), p.117-123, abr-jun.

(1972b) Aspectos sociais da literatura brasileira. Revista Brasileira de Cultura.

Rio de Janeiro: MEC, p.147-160.

(1974). A liçào. In:-. Contos. Antologia. Rio de Janeiro: Francisco Alves.

(1976) Sul da Babia: chão de cacau. Rio de Janeiro: Civilizaçào Brasileira.

(1977a) Luanda Beira Bahia. 3. ed. Rio de Janeiro: Civilizaçào Brasileira, (Coleçào Vera Cruz, 157).

(1977b) O romance O quinze. In: Queiroz, Rachel de. O quinze. 22. ed. Rio de Janeiro: José Olímpio, p. 14-20.

(1978a) Memóriss de I ázuro. 5. ed. Rio de Janeiro: Civilizaçào Brasileira. 
(1978b) Espaço, tempo e existência. In: Condé, José. Vento ao Amanhecer em Macambira. Rio de Janeiro: Civilizaçào Brasileira; Brasília: INL, (obras escolhidas de José Condé, V).

(1978c) Fora da Pista. 2. ed. Rio de Janeiro: Civilizaçào Brasileira, (Coleçào Vera Cruz, 263).

(1979) Os servos da morte. 5. ed. Rio de Janeiro: Civilizaçào Brasileira.

(1980) Apresentação. . Anais da Biblioteca Nacional. Rio de Janeiro: 80.

(1981a) O largo da Pulma. Rio de Janeiro: Civilizaçào Brasileira, (Coleção Vera Cruz, 325).

(1981b) Auto dos I/héus. Rio de Janeiro: Civilizaçào Brasileira, 48p.

(1982a) Léguas da Promissão. 9. ed. Sào Paulo: Difel.

(1982b) As velhas. Sào Paulo: Difel.

(1983a) O Forte. 7. ed. Sào Paulo: Difel.

(1983b) Noite sem madrugada. Sào Paulo: Difel.

(1984) Afrânio Coutinho. In: - Miscelânea de estudos literários. Homenagem a Afrânio Coutinho. Rio de Janeiro: Pallas; Brasília: INL, p. 409-410.

(1987). Adonias por Adonias. Revista da Academia de Letras da Babia, n" 34, Salvador.

(1988) Corpo I 'ivo. 22. ed. Rio de Janeiro: Bertrand Brasil.

(s.d.) Aristóteles, simbolo da sabedoria bumana. Rio de Janeiro: Ediçòes de Ouro, (série História).

(s.d.) Uma nota de cem. Rio de Janeiro: Ediçòes Ouro, (Coleçào Calouro). 